Supplementary material to the article:

\title{
Breast and cervical cancer screening attendance among Czech women
}

Anna Altová ${ }^{1}$ Ivana Kulhánová ${ }^{1,2}$, Lukáš Brůha $^{3}$, Michala Lustigová $^{2,4}$

${ }^{1}$ Department of Demography and Geodemography, Faculty of Science, Charles University, Prague, Czech Republic

${ }^{2}$ Department of Social Geography and Regional Development, Faculty of Science, Charles University, Prague, Czech Republic

${ }^{3}$ Department of Applied Geoinformatics and Cartography, Faculty of Science, Charles University, Prague, Czech Republic

${ }^{4}$ National Institute of Public Health, Prague, Czech Republic

Contact:

Anna Altová

anna.altova@natur.cuni.cz

Albertov 6, Prague 2, 128 00, Czech Republic 
Table S1: Standardized cervical cancer screening attendance rate (\%) by LAU 1 region, Czech women, 20092017

Standardized attendance rate (\%)

\begin{tabular}{|c|c|c|c|c|c|c|c|c|c|c|}
\hline District & LAU 1 & 2009 & 2010 & 2011 & 2012 & 2013 & 2014 & 2015 & 2016 & 2017 \\
\hline Czechia & CZO & 41.0 & 43.1 & 44.0 & 44.0 & 45.4 & 45.0 & 45.8 & 45.8 & 45.9 \\
\hline Prague & CZO100 & 36.5 & 39.2 & 39.2 & 39.4 & 40.5 & 40.4 & 41.2 & 41.1 & 40.6 \\
\hline Benešov & CZO201 & 43.4 & 45.3 & 46.4 & 47.1 & 48.1 & 47.8 & 48.6 & 48.5 & 49.2 \\
\hline Beroun & CZO2O2 & 37.3 & 37.7 & 39.1 & 39.8 & 40.8 & 40.5 & 40.5 & 43.2 & 41.2 \\
\hline Kladno & CZO203 & 36.1 & 41.3 & 40.7 & 41.0 & 42.2 & 42.3 & 43.2 & 43.3 & 43.4 \\
\hline Kolín & CZO204 & 42.3 & 42.9 & 43.8 & 43.6 & 45.0 & 45.0 & 46.1 & 47.3 & 47.3 \\
\hline Kutná Hora & CZO205 & 41.2 & 42.2 & 43.7 & 40.6 & 43.2 & 42.8 & 45.5 & 43.7 & 45.0 \\
\hline Mělník & CZO206 & 41.7 & 43.8 & 44.3 & 44.0 & 44.5 & 45.5 & 45.0 & 46.9 & 46.5 \\
\hline Mladá Boleslav & CZO207 & 38.1 & 41.2 & 43.6 & 43.1 & 43.1 & 43.8 & 44.0 & 43.2 & 43.5 \\
\hline Nymburk & CZO208 & 41.3 & 41.7 & 42.8 & 42.3 & 42.7 & 43.6 & 42.9 & 43.0 & 42.8 \\
\hline Prague East & CZO209 & 40.7 & 41.8 & 43.1 & 43.0 & 44.0 & 43.6 & 45.4 & 46.0 & 45.9 \\
\hline Prague West & CZO20A & 40.6 & 43.0 & 43.4 & 42.9 & 44.7 & 44.4 & 45.4 & 45.8 & 45.6 \\
\hline Příbram & CZO20B & 46.8 & 46.9 & 49.1 & 47.8 & 49.5 & 50.0 & 49.5 & 51.1 & 50.7 \\
\hline Rakovník & CZO20C & 44.8 & 47.8 & 48.9 & 48.0 & 50.8 & 50.2 & 51.9 & 51.0 & 52.9 \\
\hline Č. Budějovice & CZO311 & 44.1 & 45.9 & 46.5 & 46.6 & 48.5 & 49.3 & 49.1 & 49.3 & 49.9 \\
\hline Č. Krumlov & CZ0312 & 46.9 & 49.7 & 49.3 & 50.1 & 52.7 & 51.4 & 53.7 & 53.5 & 54.2 \\
\hline Jindřichův Hradec & CZ0313 & 52.6 & 52.7 & 54.1 & 53.8 & 54.4 & 54.2 & 54.2 & 55.2 & 55.0 \\
\hline Písek & CZO314 & 43.8 & 45.1 & 46.5 & 45.2 & 48.1 & 46.5 & 48.1 & 47.4 & 48.2 \\
\hline Prachatice & CZ0315 & 42.4 & 41.7 & 44.0 & 42.7 & 44.8 & 44.0 & 43.6 & 44.8 & 43.2 \\
\hline Strakonice & CZ0316 & 41.0 & 41.6 & 42.3 & 41.7 & 43.5 & 43.0 & 44.3 & 43.8 & 44.1 \\
\hline Tábor & CZ0317 & 51.6 & 51.8 & 51.6 & 50.9 & 53.9 & 50.7 & 52.0 & 52.3 & 51.5 \\
\hline Domažlice & CZO321 & 45.4 & 47.6 & 51.1 & 51.1 & 52.5 & 51.9 & 53.4 & 53.2 & 53.7 \\
\hline Klatovy & CZO322 & 42.6 & 42.7 & 44.5 & 43.8 & 46.7 & 45.8 & 47.1 & 46.5 & 47.4 \\
\hline Plzeň City & CZO323 & 42.9 & 41.2 & 46.3 & 45.6 & 48.3 & 46.6 & 47.3 & 46.8 & 46.7 \\
\hline Plzeň South & CZO324 & 45.2 & 44.5 & 49.5 & 49.4 & 51.1 & 50.5 & 50.9 & 50.7 & 50.0 \\
\hline Plzeň North & CZO325 & 45.0 & 44.1 & 47.7 & 47.9 & 49.5 & 49.6 & 49.4 & 49.2 & 49.0 \\
\hline Rokycany & CZO326 & 39.5 & 40.2 & 43.0 & 43.3 & 44.2 & 44.0 & 45.1 & 45.1 & 44.7 \\
\hline Tachov & CZO327 & 49.2 & 49.1 & 52.3 & 50.3 & 52.9 & 50.7 & 51.6 & 51.3 & 50.2 \\
\hline Cheb & CZ0411 & 40.1 & 39.6 & 40.7 & 40.6 & 41.5 & 42.9 & 42.5 & 43.2 & 43.0 \\
\hline Karlovy Vary & CZ0412 & 38.8 & 41.3 & 41.9 & 41.0 & 42.5 & 42.3 & 47.8 & 48.2 & 50.3 \\
\hline Sokolov & CZO413 & 45.3 & 46.5 & 47.4 & 45.9 & 47.1 & 47.1 & 50.1 & 49.8 & 51.2 \\
\hline Děčín & CZO421 & 36.3 & 38.8 & 37.7 & 40.3 & 41.1 & 41.9 & 42.4 & 43.3 & 44.2 \\
\hline Chomutov & CZO422 & 37.7 & 44.0 & 45.1 & 46.3 & 48.1 & 46.4 & 47.6 & 47.9 & 48.9 \\
\hline Litoměřice & CZO423 & 44.4 & 47.0 & 47.3 & 47.9 & 47.7 & 49.8 & 49.4 & 51.2 & 51.0 \\
\hline Louny & CZO424 & 37.7 & 41.1 & 42.5 & 42.4 & 43.3 & 43.6 & 46.0 & 46.2 & 45.5 \\
\hline Most & CZO425 & 43.1 & 46.1 & 44.4 & 45.4 & 47.2 & 45.3 & 45.9 & 46.1 & 46.6 \\
\hline Teplice & CZO426 & 32.4 & 35.9 & 36.8 & 38.8 & 40.6 & 40.4 & 42.2 & 43.3 & 45.1 \\
\hline Ústí n. Labem & CZ0427 & 35.6 & 35.5 & 37.8 & 37.2 & 40.1 & 38.8 & 40.7 & 41.9 & 43.3 \\
\hline
\end{tabular}


https://doi.org/10.21101/cejph.b0144

\begin{tabular}{|c|c|c|c|c|c|c|c|c|c|c|}
\hline District & LAU 1 & 2009 & 2010 & 2011 & 2012 & 2013 & 2014 & 2015 & 2016 & 2017 \\
\hline Česká Lípa & CZ0511 & 36.8 & 42.8 & 42.9 & 42.6 & 42.6 & 43.0 & 42.7 & 43.8 & 42.6 \\
\hline Jablonec n. Nisou & CZ0512 & 47.1 & 49.0 & 48.4 & 48.4 & 49.7 & 48.5 & 48.1 & 48.5 & 46.7 \\
\hline Liberec & CZ0513 & 36.9 & 40.8 & 43.2 & 44.7 & 44.6 & 44.8 & 44.5 & 44.1 & 44.6 \\
\hline Semily & CZO514 & 46.5 & 47.9 & 48.8 & 48.1 & 49.5 & 49.7 & 50.0 & 49.9 & 49.8 \\
\hline Hradec Králové & CZO521 & 43.4 & 44.9 & 45.0 & 43.5 & 45.2 & 45.1 & 45.1 & 44.2 & 45.5 \\
\hline Jičín & CZ0522 & 47.3 & 47.9 & 48.4 & 47.1 & 50.5 & 48.9 & 50.2 & 48.1 & 50.3 \\
\hline Náchod & CZ0523 & 48.1 & 49.5 & 50.3 & 49.8 & 50.0 & 51.1 & 52.3 & 51.2 & 51.6 \\
\hline Rychnov n. Kněžnou & CZ0524 & 44.0 & 46.3 & 47.3 & 46.4 & 48.5 & 47.4 & 49.8 & 47.9 & 48.0 \\
\hline Trutnov & CZ0525 & 40.9 & 41.9 & 43.0 & 42.5 & 44.2 & 43.2 & 45.5 & 43.5 & 44.0 \\
\hline Chrudim & CZ0531 & 49.9 & 51.0 & 52.3 & 52.2 & 53.2 & 52.4 & 54.3 & 53.4 & 53.9 \\
\hline Pardubice & CZ0532 & 43.3 & 45.7 & 48.0 & 47.4 & 48.2 & 47.0 & 49.1 & 47.7 & 48.0 \\
\hline Svitavy & CZ0533 & 41.8 & 42.9 & 45.8 & 46.2 & 48.0 & 48.4 & 49.2 & 47.6 & 48.3 \\
\hline Ústí n. Orlicí & CZO534 & 45.2 & 46.7 & 47.2 & 46.8 & 47.9 & 47.9 & 49.1 & 49.0 & 47.6 \\
\hline Havlíčkův Brod & CZ0631 & 44.3 & 46.8 & 50.3 & 47.2 & 49.9 & 49.6 & 48.8 & 49.7 & 49.7 \\
\hline Jihlava & CZ0632 & 42.8 & 44.4 & 46.0 & 45.8 & 47.7 & 48.2 & 48.3 & 48.5 & 49.3 \\
\hline Pelhřimov & CZ0633 & 44.4 & 46.5 & 46.5 & 47.2 & 48.1 & 47.6 & 48.4 & 48.9 & 49.3 \\
\hline Třebíč & CZO634 & 46.6 & 45.5 & 48.6 & 48.4 & 52.0 & 50.6 & 51.3 & 50.9 & 50.9 \\
\hline Žd'ár n. Sázavou & CZ0635 & 38.6 & 44.4 & 42.4 & 44.7 & 45.7 & 43.9 & 45.4 & 44.1 & 45.4 \\
\hline Blansko & CZ0641 & 37.8 & 39.7 & 40.3 & 40.8 & 43.0 & 42.5 & 42.9 & 42.9 & 42.6 \\
\hline Brno City & CZO642 & 41.2 & 42.8 & 42.8 & 42.9 & 43.5 & 43.8 & 43.1 & 44.4 & 44.8 \\
\hline Brno County & CZ0643 & 42.3 & 43.9 & 44.4 & 44.7 & 45.5 & 45.2 & 45.2 & 46.3 & 46.7 \\
\hline Břeclav & CZ0644 & 41.8 & 43.3 & 45.4 & 44.7 & 46.0 & 44.8 & 44.8 & 44.9 & 44.5 \\
\hline Hodonín & CZO645 & 33.7 & 38.7 & 38.7 & 39.7 & 41.1 & 40.8 & 41.2 & 41.7 & 41.7 \\
\hline Vyškov & CZ0646 & 37.7 & 39.5 & 41.4 & 41.1 & 44.1 & 42.2 & 41.1 & 44.9 & 45.4 \\
\hline Znojmo & CZO647 & 40.8 & 41.0 & 41.5 & 42.4 & 42.8 & 42.5 & 42.6 & 43.9 & 44.7 \\
\hline Jeseník & CZ0711 & 32.4 & 35.1 & 35.2 & 35.7 & 34.6 & 35.9 & 36.6 & 32.8 & 32.5 \\
\hline Olomouc & CZ0712 & 40.6 & 42.7 & 43.5 & 43.9 & 44.3 & 44.8 & 45.4 & 44.9 & 44.2 \\
\hline Prostějov & CZ0713 & 38.2 & 40.4 & 41.2 & 38.9 & 41.7 & 42.6 & 42.9 & 43.7 & 44.1 \\
\hline Přerov & CZ0714 & 38.4 & 41.1 & 41.2 & 42.5 & 44.6 & 44.2 & 45.8 & 45.3 & 45.4 \\
\hline Šumperk & CZO715 & 42.6 & 46.0 & 47.7 & 47.1 & 47.9 & 47.5 & 47.5 & 49.2 & 48.4 \\
\hline Kroměřŕž & CZO721 & 38.6 & 42.2 & 41.9 & 42.6 & 44.1 & 43.5 & 44.7 & 44.7 & 45.9 \\
\hline Uherské Hradiště & CZO722 & 40.1 & 43.2 & 44.3 & 44.7 & 45.5 & 43.8 & 45.5 & 46.1 & 45.5 \\
\hline Vsetín & CZO723 & 43.3 & 46.2 & 45.9 & 46.9 & 48.5 & 47.4 & 48.9 & 49.8 & 49.4 \\
\hline Zlín & CZO724 & 40.4 & 42.3 & 43.6 & 44.5 & 45.7 & 44.4 & 44.6 & 44.2 & 44.4 \\
\hline Bruntál & CZ0801 & 44.3 & 46.3 & 46.1 & 47.2 & 47.1 & 47.5 & 46.9 & 47.0 & 47.6 \\
\hline Frýdek - Místek & CZO802 & 37.5 & 39.9 & 40.9 & 39.6 & 41.4 & 40.5 & 41.2 & 42.0 & 43.0 \\
\hline Karviná & CZ0803 & 37.2 & 39.3 & 38.8 & 38.5 & 39.4 & 39.2 & 41.6 & 40.0 & 38.9 \\
\hline Nový Jičín & CZO804 & 42.8 & 45.8 & 46.0 & 45.5 & 46.0 & 44.6 & 46.0 & 45.5 & 40.7 \\
\hline Opava & CZ0805 & 41.1 & 42.9 & 43.1 & 42.9 & 45.3 & 45.2 & 47.0 & 48.1 & 48.4 \\
\hline Ostrava City & CZ0806 & 32.1 & 36.5 & 36.8 & 36.3 & 37.6 & 36.9 & 38.3 & 36.2 & 34.8 \\
\hline
\end{tabular}


Table S2: Standardized breast cancer screening attendance rate (\%) by LAU 1 region, Czech women, 20092017

Standardized attendance rate (\%)

\begin{tabular}{|c|c|c|c|c|c|c|c|c|c|c|}
\hline District & LAU 1 & 2009 & 2010 & 2011 & 2012 & 2013 & 2014 & 2015 & 2016 & 2017 \\
\hline Czechia & CZO & 45.8 & 41.1 & 42.0 & 45.1 & 47.9 & 50.9 & 50.1 & 51.4 & 51.7 \\
\hline Prague & CZO100 & 39.1 & 34.2 & 33.3 & 37.7 & 41.8 & 43.4 & 44.2 & 43.0 & 45.6 \\
\hline Benešov & CZO201 & 53.5 & 46.0 & 46.8 & 46.6 & 50.5 & 51.8 & 52.4 & 53.8 & 54.8 \\
\hline Beroun & CZO202 & 50.1 & 42.9 & 43.0 & 45.6 & 44.9 & 52.4 & 47.6 & 54.3 & 48.8 \\
\hline Kladno & CZO203 & 40.6 & 32.8 & 35.4 & 43.0 & 43.3 & 47.6 & 45.2 & 50.2 & 51.5 \\
\hline Kolín & CZO204 & 40.1 & 36.4 & 37.4 & 40.4 & 46.0 & 50.1 & 48.3 & 49.0 & 51.1 \\
\hline Kutná Hora & CZO205 & 44.0 & 41.8 & 38.2 & 38.1 & 44.8 & 44.6 & 46.3 & 46.4 & 48.9 \\
\hline Mělník & CZO206 & 33.0 & 28.0 & 31.7 & 42.8 & 43.6 & 48.5 & 46.9 & 50.5 & 49.3 \\
\hline Mladá Boleslav & CZO207 & 38.6 & 34.3 & 38.7 & 35.1 & 39.5 & 41.2 & 39.3 & 41.8 & 41.1 \\
\hline Nymburk & CZO208 & 12.1 & 12.0 & 24.1 & 30.7 & 38.8 & 41.5 & 42.7 & 44.4 & 43.2 \\
\hline Prague East & CZO209 & 42.7 & 36.0 & 36.6 & 39.6 & 45.2 & 46.1 & 47.9 & 46.8 & 49.6 \\
\hline Prague West & CZO20A & 44.1 & 37.4 & 37.1 & 39.8 & 43.5 & 47.8 & 46.4 & 48.3 & 48.7 \\
\hline Příbram & CZO20B & 49.9 & 41.2 & 43.8 & 46.0 & 50.7 & 54.8 & 54.3 & 56.3 & 54.8 \\
\hline Rakovník & CZO2OC & 39.9 & 35.5 & 35.8 & 40.9 & 41.4 & 46.5 & 49.3 & 50.0 & 51.5 \\
\hline Č. Budějovice & CZ0311 & 52.7 & 42.7 & 45.2 & 48.5 & 48.5 & 55.3 & 51.7 & 52.8 & 52.8 \\
\hline Č. Krumlov & CZO312 & 52.4 & 39.0 & 45.3 & 46.4 & 48.8 & 50.9 & 53.3 & 50.0 & 54.0 \\
\hline Jindřichův Hradec & CZ0313 & 55.0 & 44.4 & 44.9 & 51.0 & 48.7 & 56.7 & 52.6 & 55.5 & 53.8 \\
\hline Písek & CZO314 & 66.1 & 52.2 & 52.6 & 53.4 & 52.9 & 59.4 & 58.2 & 58.1 & 59.0 \\
\hline Prachatice & CZO315 & 52.2 & 43.8 & 43.5 & 47.2 & 43.1 & 51.8 & 48.4 & 47.1 & 49.4 \\
\hline Strakonice & CZ0316 & 51.1 & 42.5 & 42.0 & 43.5 & 42.8 & 51.4 & 47.2 & 49.0 & 46.8 \\
\hline Tábor & CZ0317 & 55.1 & 53.5 & 47.3 & 54.0 & 48.9 & 59.6 & 55.3 & 55.2 & 56.0 \\
\hline Domažlice & CZ0321 & 59.5 & 53.6 & 52.1 & 54.2 & 57.8 & 56.8 & 60.5 & 59.2 & 59.6 \\
\hline Klatovy & CZO322 & 52.8 & 52.5 & 43.9 & 50.3 & 54.4 & 53.2 & 57.8 & 55.8 & 55.1 \\
\hline Plzeň City & CZO323 & 36.5 & 34.6 & 38.4 & 41.3 & 46.4 & 45.2 & 44.8 & 45.2 & 47.4 \\
\hline Plzeň South & CZO324 & 46.9 & 45.3 & 44.2 & 46.1 & 50.6 & 49.1 & 50.6 & 50.1 & 51.2 \\
\hline Plzeň North & CZO325 & 41.9 & 39.9 & 42.2 & 43.1 & 47.4 & 48.9 & 46.7 & 47.8 & 50.3 \\
\hline Rokycany & CZO326 & 42.6 & 37.3 & 41.8 & 43.0 & 47.1 & 47.4 & 49.0 & 48.9 & 48.0 \\
\hline Tachov & CZO327 & 44.6 & 43.8 & 48.4 & 47.3 & 51.2 & 51.2 & 54.5 & 51.6 & 55.3 \\
\hline Cheb & CZ0411 & 38.7 & 34.0 & 36.4 & 38.1 & 40.6 & 44.0 & 43.0 & 43.4 & 45.7 \\
\hline Karlovy Vary & CZO412 & 41.5 & 38.4 & 34.8 & 48.4 & 48.4 & 53.6 & 52.6 & 51.7 & 52.6 \\
\hline Sokolov & CZO413 & 47.3 & 49.0 & 45.6 & 50.2 & 49.5 & 54.0 & 54.9 & 55.4 & 57.0 \\
\hline Děčín & CZO421 & 50.0 & 43.7 & 43.9 & 44.9 & 50.4 & 49.0 & 49.2 & 51.2 & 50.7 \\
\hline Chomutov & CZO422 & 51.5 & 47.4 & 42.3 & 48.4 & 49.4 & 52.9 & 51.1 & 56.5 & 55.5 \\
\hline Litoměřice & CZO423 & 39.2 & 36.7 & 40.3 & 42.5 & 49.2 & 54.3 & 52.5 & 54.5 & 53.6 \\
\hline Louny & CZO424 & 24.3 & 25.4 & 31.6 & 37.2 & 40.2 & 41.5 & 43.6 & 44.5 & 46.7 \\
\hline Most & CZO425 & 34.6 & 31.5 & 36.4 & 46.8 & 44.1 & 52.1 & 48.0 & 54.9 & 51.7 \\
\hline Teplice & CZO426 & 34.4 & 33.8 & 32.9 & 37.3 & 40.0 & 45.4 & 46.1 & 49.9 & 48.5 \\
\hline Ústí n. Labem & CZ0427 & 35.8 & 36.6 & 32.9 & 37.4 & 40.8 & 43.9 & 44.7 & 44.3 & 46.1 \\
\hline
\end{tabular}


https://doi.org/10.21101/cejph.b0144

\begin{tabular}{|c|c|c|c|c|c|c|c|c|c|c|}
\hline District & LAU 1 & 2009 & 2010 & 2011 & 2012 & 2013 & 2014 & 2015 & 2016 & 2017 \\
\hline Česká Lípa & CZ0511 & 44.7 & 45.6 & 42.8 & 46.3 & 52.9 & 47.9 & 53.0 & 48.3 & 62.4 \\
\hline Jablonec n. Nisou & CZ0512 & 47.2 & 47.0 & 48.3 & 46.4 & 51.4 & 51.9 & 48.9 & 55.3 & 49.5 \\
\hline Liberec & CZ0513 & 40.2 & 42.5 & 43.5 & 41.9 & 48.4 & 49.5 & 48.4 & 51.4 & 49.8 \\
\hline Semily & CZ0514 & 36.9 & 30.7 & 35.6 & 38.4 & 40.8 & 40.7 & 40.1 & 40.0 & 43.4 \\
\hline Hradec Králové & CZ0521 & 47.2 & 42.6 & 44.8 & 46.2 & 48.0 & 50.5 & 52.0 & 50.3 & 53.3 \\
\hline Jičín & CZ0522 & 60.3 & 45.9 & 46.1 & 47.3 & 50.6 & 51.4 & 50.7 & 51.8 & 50.1 \\
\hline Náchod & CZ0523 & 58.8 & 48.8 & 46.4 & 49.1 & 52.8 & 56.0 & 54.3 & 54.4 & 53.2 \\
\hline Rychnov n. Kněžnou & CZ0524 & 51.0 & 46.9 & 43.5 & 49.3 & 46.8 & 57.3 & 54.8 & 54.4 & 51.4 \\
\hline Trutnov & CZ0525 & 32.6 & 28.3 & 35.6 & 37.8 & 40.7 & 42.9 & 39.0 & 33.8 & 46.8 \\
\hline Chrudim & CZ0531 & 40.5 & 36.9 & 33.1 & 39.7 & 36.2 & 46.7 & 51.1 & 55.5 & 52.0 \\
\hline Pardubice & CZ0532 & 34.4 & 29.6 & 28.5 & 34.1 & 37.3 & 43.4 & 45.6 & 47.0 & 46.7 \\
\hline Svitavy & CZ0533 & 61.1 & 49.4 & 51.3 & 53.6 & 53.3 & 54.8 & 56.0 & 55.9 & 56.0 \\
\hline Ústí n. Orlicí & CZ0534 & 45.1 & 41.6 & 39.7 & 45.7 & 50.1 & 54.4 & 54.1 & 53.5 & 53.0 \\
\hline Havlíčkův Brod & CZ0631 & 55.4 & 49.5 & 45.4 & 48.4 & 46.6 & 54.5 & 52.9 & 54.6 & 54.6 \\
\hline Jihlava & CZ0632 & 58.5 & 53.4 & 50.9 & 53.9 & 57.3 & 58.7 & 60.7 & 57.4 & 62.0 \\
\hline Pelhřimov & CZ0633 & 74.2 & 61.4 & 61.9 & 65.6 & 63.1 & 67.5 & 66.2 & 67.4 & 61.8 \\
\hline Třebíč & CZ0634 & 62.3 & 58.8 & 71.8 & 59.3 & 73.2 & 63.6 & 71.9 & 67.0 & 69.8 \\
\hline Žd'ár n. Sázavou & CZ0635 & 62.7 & 49.0 & 53.2 & 55.3 & 59.2 & 61.9 & 60.0 & 61.6 & 59.6 \\
\hline Blansko & CZ0641 & 61.0 & 51.9 & 51.0 & 52.8 & 52.7 & 54.5 & 55.4 & 58.3 & 55.6 \\
\hline Brno City & CZ0642 & 52.8 & 52.2 & 47.9 & 50.2 & 52.5 & 54.6 & 53.3 & 53.1 & 54.8 \\
\hline Brno Country & CZ0643 & 53.3 & 51.3 & 46.7 & 50.6 & 51.2 & 55.5 & 52.9 & 54.1 & 53.8 \\
\hline Břeclav & CZO644 & 68.0 & 55.5 & 53.5 & 49.0 & 52.8 & 56.1 & 52.7 & 54.7 & 56.4 \\
\hline Hodonín & CZ0645 & 42.8 & 37.4 & 34.2 & 49.4 & 43.3 & 50.7 & 49.1 & 49.2 & 49.0 \\
\hline Vyškov & CZ0646 & 54.2 & 46.1 & 44.8 & 46.9 & 47.8 & 51.1 & 51.4 & 52.5 & 52.4 \\
\hline Znojmo & CZ0647 & 50.1 & 47.2 & 44.3 & 47.1 & 49.0 & 51.6 & 49.0 & 52.7 & 51.0 \\
\hline Jeseník & CZ0711 & 29.1 & 36.7 & 32.0 & 37.7 & 36.2 & 45.6 & 39.2 & 42.4 & 38.3 \\
\hline Olomouc & CZ0712 & 36.8 & 45.3 & 48.5 & 49.7 & 51.9 & 53.9 & 53.8 & 57.0 & 54.1 \\
\hline Prostějov & CZ0713 & 30.2 & 31.6 & 31.0 & 40.5 & 43.0 & 47.6 & 44.8 & 48.4 & 48.5 \\
\hline Přerov & CZ0714 & 57.9 & 47.5 & 48.5 & 47.6 & 64.8 & 59.1 & 60.3 & 62.0 & 62.3 \\
\hline Šumperk & CZ0715 & 47.3 & 48.7 & 48.1 & 51.9 & 49.2 & 60.5 & 54.7 & 55.3 & 57.0 \\
\hline Kroměřŕž & CZ0721 & 59.0 & 50.9 & 53.2 & 55.3 & 59.2 & 59.7 & 59.3 & 62.7 & 58.4 \\
\hline Uherské Hradiště & CZ0722 & 44.6 & 44.0 & 45.3 & 48.4 & 51.1 & 54.6 & 51.2 & 55.2 & 52.0 \\
\hline Vsetín & CZ0723 & 54.3 & 39.9 & 48.5 & 56.2 & 52.8 & 56.5 & 50.2 & 61.5 & 51.9 \\
\hline Zlín & CZO724 & 30.2 & 25.8 & 46.4 & 47.6 & 43.9 & 59.7 & 48.7 & 55.7 & 53.8 \\
\hline Bruntál & CZ0801 & 35.7 & 37.6 & 36.8 & 43.6 & 44.1 & 47.6 & 47.1 & 47.4 & 46.8 \\
\hline Frýdek - Místek & CZO802 & 42.2 & 31.2 & 38.8 & 38.4 & 45.1 & 45.5 & 39.3 & 45.3 & 42.7 \\
\hline Karviná & CZ0803 & 34.3 & 32.2 & 35.7 & 34.1 & 41.6 & 41.8 & 39.4 & 43.7 & 47.7 \\
\hline Nový Jičín & CZO804 & 57.3 & 49.6 & 55.6 & 52.5 & 55.9 & 50.9 & 51.7 & 54.3 & 53.1 \\
\hline Opava & CZO805 & 52.9 & 48.7 & 45.2 & 47.8 & 52.6 & 52.0 & 54.3 & 52.7 & 53.8 \\
\hline Ostrava City & CZ0806 & 42.0 & 36.3 & 39.0 & 36.2 & 44.7 & 45.5 & 45.7 & 46.5 & 45.5 \\
\hline
\end{tabular}

